\title{
Endoscopic Internal Urethrotomy Outcomes in the Management of Male Urethral Strictures
}

\author{
Roland Bertille Banga Mouss, Aristide Stève Ondziel Opara, Armel Melvin Ondongo Atipo, \\ Yannick I. Dimi Nianga, F. C. Btchiv, Joseph Damba, J. P. Otilibili, Anani Wencesl Séverin Odzébé*, \\ Prosper Alain Bouya
}

Department of Urology and Andrology of the University Hospital of Brazzaville, Brazzaville, Congo

Email: *odzebe_s@yahoo.fr

How to cite this paper: Banga Mouss, R.B., Ondziel Opara, A.S., Ondongo Atipo, A.M., Dimi Nianga, Y.I., Btchiv, F.C., Damba, J., Otilibili, J.P., Odzébé, A.W.S. and Bouya, P.A. (2021) Endoscopic Internal Urethrotomy Outcomes in the Management of Male Urethral Strictures. Open Journal of Urology, 11, 452-457. https://doi.org/10.4236/oju.2021.1112045

Received: August 10, 2021

Accepted: December 12, 2021

Published: December 15, 2021

Copyright $\odot 2021$ by author(s) and Scientific Research Publishing Inc. This work is licensed under the Creative Commons Attribution International License (CC BY 4.0).

http://creativecommons.org/licenses/by/4.0/

\begin{abstract}
Background: The aim of this study was to evaluate the outcomes of stricture treatment using endoscopic internal urethrotomy in the male urethra. Patients and Methods: We conducted a retrospective study from 2012 to 2017 at the Urology and Andrology Department of the University Hospital in Brazzaville, Congo. Medical records of 30 patients who underwent endoscopic internal urethrotomy for urethral stricture were analyzed. We studied the following variables: frequency of urethral stricture, age of patient, onset, cause and location of urethral stricture, duration of bladder catheterization, duration of hospitalization, and postoperative complications. The treatment outcome was assessed after a follow-up of 2.6 years (extreme: 2 and 4 years). Outcomes were considered successful or good when the patients had a normal urine flow and an unobstructed urethra at the Retrograde Urethrogram (RUG). Results: The mean age was $47.5 \pm 9.7$ years (range: 17 to 83 years). Dysuria was the most common symptom reported. We found that urethral stricture was mostly caused by infectious diseases (20 patients). The urethral stricture was located at the membranous urethra in 4 patients, the bulbar urethra in 25 patients, and the penile urethra in 1 patient. The mean duration of the bladder catheterization was 2.3 days. Hospitalization duration was 36 hours. We observed the following complications: urethrorrhagia in 3 patients, acute orchiepididymitis. We achieved good results in 23 patients. Conclusion: In our context where the practice of endoscopic internal urethrotomy is recent, it provides satisfactory results for the treatment of short urethral male stricture.
\end{abstract}

\section{Keywords}

Stricture, Male Urethra, Endoscopic Internal Urethrotomy 


\section{Introduction}

Urethral stricture is an intrinsic and permanent decrease in the caliber of the urethra, which leads to an obstruction in the flow of urine. Sexually transmitted infection and urethra trauma are the main causes reported in the literature. Diverse treatments options for male urethral stricture exist, which include endoscopic internal urethrotomy (EIU), urethroplasty and bougienage [1].

Urethroplasty is an invasive method of treatment for urethral stricture, which carries the risk of male sexual dysfunction and deformation of the penis. Bougienage technique is not used in our context because of lack of equipment. EIU technique involves a high rate of recurrences, especially when the stricture is greater than $1 \mathrm{~cm}$. However, in our context, EIU remains the most practical and accessible option for the treatment of urethral stricture [2]. Since EIU is carried out, no study has been able to evaluate its results. This is how we proposed to carry out this study with the aim to evaluate the outcomes of EIU treatment for male stricture.

\section{Patients and Methods}

We conducted a retrospective study from 2012 to 2017 at the Urology and Andrology Department of the University Hospital in Brazzaville-Congo. We focused on the medical records of patients who were hospitalized for urethral stricture and underwent EIU. The inclusion criteria for this study were: availability of medical observation, RUG results, operative report and postoperative follow-up data. In addition, we considered patients with a unique stricture $<1 \mathrm{~cm}$ length and no presence of spongiofibrosis. On the basis of these criteria, 30 medical records were selected. A Cytobacteriological Exam of Urine (ECBU) was performed preoperatively to ensure the absence of urinary tract infection. The urethrotomy was performed using a Woolf brand urethrotomy fitted with a $0^{\circ}$ optical urethrotomy. The stricture was catheterized by a guidewire, and the incision was made at the 12 o'clock position. The procedure ended with the insertion of an indwelling urethral catheter. We studied the following variables: frequency of urethral stricture; age of patients; onset; cause and location of urethral stricture; procedure duration, bladder catheterization duration; hospitalization duration; and post-operative complications. The treatment outcome was assessed after a follow-up of 2.6 years (with extremes of 2 and 4 years). Outcomes were considered successful or good when the patients had a normal urine flow and an unobstructed urethra at the RUG. Conversely, it was considered unsuccessful or poor when patients had dysuria and a RUG showing a narrowed urethra.

Data entry and processing were carried out using Epi-info software version 7.2.2.6 The various tables and graphs were generated using the Microsoft Office Excel 2016 software. For quantitative variables, we calculated means and standard deviations.

\section{Results}

During the study period, 2610 patients were admitted into the Urology-Andrology 
department, of which 80 patients were treated for urethral stricture. Among these patients, 30 underwent an internal endoscopic urethrotomy. The mean age was $47.5 \pm 9.7$ years (extremes 17 and 83 years). The most common symptoms reported were dysuria (19 patients), followed by urinary retention ( 7 patients) and pollakiuria (4 patients). We found that male urethral strictures were mostly caused by infections ( 20 patients). The other causes were urethral trauma ( $7 \mathrm{pa}-$ tients) and iatrogenic lesions due to bladder catheterization (3 patients).

Among these patients who had post-traumatic urethral strictures, 3 were the consequence of a pelvic trauma due to car accident, which involved membranous urethra, and 4 were due to perineal trauma, which involved bulbar urethra (perineal).

RUG results showed that all patients had a unique stricture with a length less than $1 \mathrm{~cm}$ in our study. Urethral strictures were located in 3 different areas: bulbar urethra (25 patients), membranous urethra (4 patients), and penile urethra (1 patient).

Twenty-six patients had anterior urethral strictures and 4 patients had posterior urethral strictures.

The mean duration of the procedure was 16.7 minutes (extremes 6 and 25 minutes). The mean duration of the bladder catheterization was 2.3 days (extremes of 1 and 5 days). Hospitalization duration was 36 hours (extremes 24 and 72 hours). We observed the following complications: urethrorrhagia in 3 patients, acute orchiepididymitis in 1 patient, successfully treated with fluoroquinolone.

Outcomes were considered successful or good in 23 patients and poor in $7 \mathrm{pa}-$ tients. Among those successfully treated, 22 had an anterior urethral stricture (Table 1).

\section{Discussion}

Male urethral stricture is a common condition. The treatment depends on the location, the cause, the length of the stricture, and the availability of the technical equipment. Treatment methods include minimally invasive techniques (dilation, EIU) and surgical reconstructions using a flap or graft [3] [4]. EIU is indicated for the treatment of a short stricture less than $1 \mathrm{~cm}$ in length, and it is performed using a urethrotome [2] [5] [6]. Following the procedure, a catheter is inserted for 8 to 24 hours. The duration of the bladder catheterization is controversial; some authors like Chiari [7] are in favor of prolonged bladder catheterization,

Table 1. Distribution of UIE results according to the sites of urethral stricture.

\begin{tabular}{ccc}
\hline & Good results & Bad results \\
\hline Bulbar urethra & $71 \%$ & $13 \%$ \\
Membranous urethra & $3 \%$ & $10 \%$ \\
Penile urethra & $3 \%$ & 0 \\
\hline
\end{tabular}


while other authors, like Johnston [8], are in favor of a short catheterization. In our practice, our preference is a short catheterization period.

EIU Stricture treatment was successful in 23 patients, which represents $77 \%$. Similar trends have been reported by Benjelloun in Morocco [9], Guirassy in Guinea [10], and Dje in the Ivory Coast [11]. The hospitalization duration was 36 hours, which is shorter than other studies that reported duration of 6.8 and 6 days respectively [11] [12].

In our study, $10 \%$ of our patients experienced complications related to the procedure. Urethrorrhagia was the main complication in our study; however, it didn't require a transfusion. Other authors reported higher bleeding rates, and it was due to the existence of other per operative complications [11] [12].

We found one infectious complication in our study, which was an orchiepididymitis. Dje et al. [11] reported that $83 \%$ of postoperative complications were infectious, and orchiepididymitis represented $1 \%$ of the cases.

We obtained successful outcomes in 23 patients. Our results were similar to those reported by Mhiri [13]. However, other studies found a higher failure rate [11]. A successful outcome of an EIU depends on the cause, location, and length of the stricture. For Dubey [14], traumatic strictures have a higher rate of failure than sclero-inflammatory strictures, which is consistent with what we reported in our study. Failures were observed $43 \%$ in traumatic strictures and $20 \%$ in infectious strictures. Mhiri [13] reported contrasting results.

Regarding the location of the stricture, outcomes were better when the stricture was at the proximal urethra [15]. In our study, we reported better results for anterior urethral strictures in 22 cases.

In order to achieve successful results, we believe that the length of the stricture should be considered when planning EIU procedure. Normally, EIU should be limited to urethral stricture of less than $1 \mathrm{~cm}$. Isen et al. [16], who performed EIU in that indication, obtained $86.8 \%$ of good results in the 3 months, and only $14.2 \%$ of patients required a second urethrotomy. In our study, the majority of patients had urethral stenosis small size, a good indication for EID while in Yameogo et al. [17], stenosis of the urethra was very extensive which is why open surgery was the only indication. Our study reported a $77 \%$ success rate and a $23 \%$ failure rate in the first EIU cases. Of these, 17\% required a second EIU and $7 \%$ required dilation with Van Buren Sounds.

The study is carried out retrospectively, with a limited number of patients related to the conditions of selection, excluding certain files due to lack of information, and on the basis of exploitation of the records of a single department. It is therefore not representative of all patients operated in Congo by EID for urethral stricture. Its cross-sectional nature and small sample size limit the scope of its conclusions.

\section{Conclusion}

Endoscopic internal urethrotomy is a simple treatment method for male urethral 
stricture. It is associated with few complications. In our context where the practice of endoscopic internal urethrotomy is recent, it provides satisfactory results for the treatment of short urethral male stricture and should be recommended as first-line treatment for these types of lesions.

\section{Conflicts of Interest}

The authors declare no conflicts of interest regarding the publication of this paper.

\section{References}

[1] Verla, W., Oosterlinck, W., Spinoit, A.F. and Waterloos, M. (2019) A Comprehensive Review Emphasizing Anatomy, Etiology, Diagnosis, and Treatment of Male Urethral Stricture Disease. BioMed Research International, 2019, Article ID: 9046430. https://doi.org/10.1155/2019/9046430

[2] Shoukry, A.I., Abouela, W.N., ElSheemy, M.S., Shouman, A.M., Daw, K., Hussein, A.A., et al. (2016) Use of Holmium Laser for Urethral Strictures in Pediatrics: A Prospective Study. Journal of Pediatric Urology, 12, 42.E1-42.E6. https://doi.org/10.1016/j.jpurol.2015.06.016

[3] Hampson, L.A., McAninch, J.W. and Breyer, B.N. (2014) Male Urethral Strictures and Their Management. Nature Reviews Urology, 11, 43-50. https://doi.org/10.1038/nrurol.2013.275

[4] Ather, M.H., Zehri, A.A., Soomro, K. and Nazir, I. (2009) The Safety and Efficacy of Optical Urethrotomy Using a Spongiosum Block with Sedation: A Comparative Nonrandomized Study. Journal of Urology, 181, 2134-2138. https://doi.org/10.1016/j.juro.2009.01.017

[5] Munks, D.G, Alli, M.O. and Goad, E.H. (2010) Optical Urethrotomy under Local Anaesthesia Is a Feasible Option in Urethral Stricture Disease. Tropical Doctor, 40, 31-32. https://doi.org/10.1258/td.2009.090121

[6] Anger, J.T., Buckley, J.C., Santucci, R.A., Elliott, S.P. and Saigal, C.S. (2011) Trends in Stricture Management among Male Medicare Beneficiaries: Underuse of Urethroplasty? Urology, 77, 481-485. https://doi.org/10.1016/j.urology.2010.05.055

[7] Chiari, R., Funke, P., Fluchter, S. and Planz, K. (1978) Interne Urethrotomie und Katheterverweilzeit: Langzettergebnise. Aktuelle Urologie, 8, 327-329.

[8] Johnston, S., Bagshaw, H., Flynn, J., Kellett, M. and Blandy, J. (1980) Visual Internal Urethrotomy. British Journal of Urology, 52, 542-545. https://doi.org/10.1111/j.1464-410X.1980.tb03111.x

[9] Benjelloun, M., Drissi, M., Makhloufi, M., Nouri, A., Karmouni, T., Tazi, K., Elkhader, K., Koutani, A., Benatya, A. and Hachimi, M. (2008) Treatment of Utrthral Strictures Bay Endoscopic Internal Urthrotomy: Anatomical and Functional Results in a Series of 244 Cases. African Journal of Urology, 14, 114-119. https://doi.org/10.1007/s12301-008-0002-3

[10] Guirassy, S. (1992) Retrospective Study of Urethral Stricture at the Department of Urology of the Ignace-Deen University Hospital. January 1985-October 1990. Journal of Urology, 98, 101-104.

[11] Dje, K., Coulibaly, A., Coulibaly, N. and Sangare, I.S. (1999) Endoscopic Internal Urethrotomy in the Treatment of Acquired Black Urethral Stricture in 140 Cases. Médecine d Afrique Noire, 46, 56-61. 
[12] Zango, B., Kambou, T. and Sanou, A. (2003) Internal Endoscopic Urethrotomy for Urethral Stricture at the Hospital of Bobo-Dioulasso: Feasibility of the Technique in Precarious Situations and Short-Term Results. Bulletin de la Société de Pathologie Exotique, 96, 92-95.

[13] Mhiri, C.H., Mhiri, M.N. and Smida, I. (1992) Urethral Strictures about 158 Cases. La Tunisie Medicale, 70, 513-519.

[14] Dubey, D. (2011) The Current Role of Direct Vision Internal Urethrotomy and Self-Catheterization for Anterior Urethral Strictures. Indian Journal of Urology, 27, 392-396. https://doi.org/10.4103/0970-1591.85445

[15] Guyrassy, S., Simakan, N.F., Sow, K.B., Balde, S., Bah, I., Diabate, I., et al. (2001) Endoscopic Internal Urethrotomy for the Treatment of Stenosis of the Urethra in the Urology Department of CHU Ignace Deen. Annales d Urologie, 35, 167-171. https://doi.org/10.1016/S0003-4401(01)00022-5

[16] Isen, K. and Nalçacioğlu, V. (2015) Direct Vision Internal Urethrotomy by Using Endoscopic Scissors. International Urology and Nephrology, 47, 905-908. https://doi.org/10.1007/s11255-015-0960-x

[17] Yameogo, C., Ouattara, A., Kaboré, F., Ky, B., Bougayiri, A., Traoré, O., et al. (2017) Male Anterior Urethral Stricture: Epidemiological Profile and Management at Ouagadougou University Teaching Hospital (Burkina-Faso). Open Journal of Urology, 7, 196-206. https://doi.org/10.4236/oju.2017.711023 